\title{
Advances in global sensitivity analyses of demographic-based species distribution models to address uncertainties in dynamic landscapes
}

\author{
Ilona Naujokaitis-Lewis ${ }^{\text {Corresp., }}{ }^{1}$, Janelle M.R. Curtis ${ }^{2}$ \\ 1 National Wildlife Research Centre, Carleton University, Environment and Climate Change Canada, Ottawa, Ontario, Canada \\ 2 Conservation Biology Section, Pacific Biological Station, Fisheries and Oceans Canada, Nanaimo, British Columbia, Canada \\ Corresponding Author: Ilona Naujokaitis-Lewis \\ Email address: ilona.naujo.lewis@gmail.com
}

Developing a rigorous understanding of multiple global threats to species persistence requires the use of integrated modeling methods that capture processes which influence species distributions. Species distribution models (SDMs) coupled with population dynamics models can incorporate relationships between changing environments and demographics and are increasingly used to quantify relative extinction risks associated with climate and land-use changes. Despite their appeal, uncertainties associated with complex models can undermine their usefulness for advancing predictive ecology and informing conservation management decisions. We developed a computationally-efficient and freely available tool (GRIP 2.0) that implements and automates a global sensitivity analysis of coupled SDM-population dynamics models for comparing the relative influence of demographic parameters and habitat attributes on predicted extinction risk. Advances over previous global sensitivity analyses include the ability to vary habitat suitability across gradients, as well as habitat amount and configuration of spatially-explicit suitability maps of real and simulated landscapes. Using GRIP 2.0, we carried out a multimodel global sensitivity analysis of a coupled SDM-population dynamics model of whitebark pine (Pinus albicaulis) in Mount Rainier National Park as a case study and quantified the relative influence of input parameters and their interactions on model predictions. Our results differed from the one-at-time analyses used in the original study, and we found that the most influential parameters included the total amount of suitable habitat within the landscape, survival rates, and effects of a prevalent disease, white pine blister rust. Strong interactions between habitat amount and survival rates of older trees indicated the importance of habitat in mediating the negative influences of white pine blister rust. Our results underscore the importance of considering habitat attributes along with demographic parameters in sensitivity routines. GRIP 2.0 is an important decisionsupport tool that can be used to prioritize research, identify habitat-based thresholds and 
management intervention points to improve probability of species persistence, and evaluate trade-offs of alternative management options. 
1 Advances in global sensitivity analyses of demographic-based species distribution models to

2 address uncertainties in dynamic landscapes

3

4 NAUJOKAITIS-LEWIS, ILONA ${ }^{1,2}$, and Janelle M. R. Curtis ${ }^{1,3}$

5

$6 \quad{ }^{1}$ Centre for Applied Conservation Research, University of British Columbia, 2424 Main Mall,

7 Vancouver, British Columbia, Canada V6T 1Z4

8 (ilona.naujokaitis-lewis@canada.ca)

9

10 Present address of Ilona Naujokaitis-Lewis:

$11{ }^{2}$ National Wildlife Research Centre, Environment and Climate Change Canada, Carleton

12 University, Ottawa, Ontario, Canada

13

$14{ }^{3}$ Pacific Biological Station, Fisheries and Oceans Canada, Nanaimo, British Columbia, Canada 


\section{Abstract}

18 Developing a rigorous understanding of multiple global threats to species persistence requires the use of integrated modeling methods that capture the processes that influence species distributions. Species distribution models (SDMs) coupled with population dynamics models can incorporate relationships between changing environments and demographics and are increasingly used to quantify relative extinction risks associated with climate and land-use changes. Despite their appeal, uncertainties associated with complex models can undermine their usefulness for advancing predictive ecology and informing conservation management decisions. We developed a computationally-efficient and freely available tool (GRIP 2.0) that implements and automates a global sensitivity analysis of coupled SDM-population dynamics models for comparing the relative influence of demographic parameters and habitat attributes on predicted extinction risk. Advances over previous global sensitivity analyses include the ability to vary habitat suitability, as well as the amount and configuration of suitable habitat in spatially-explicit suitability maps of real and simulated landscapes. Using GRIP 2.0, we carried out a multi-model global sensitivity analysis of a coupled SDM-population dynamics model of whitebark pine (Pinus albicaulis) in Mount Rainier National Park as a case study and quantified the relative influence of input parameters and their interactions on model predictions. Our results differed from the one-at-time analyses used in the original study, and we found that the most influential parameters included the total amount of suitable habitat within the landscape, survival rates, and effects of a prevalent disease, white pine blister rust. Strong interactions between habitat amount and survival rates of older trees indicated the importance of habitat in mediating the negative influences of white pine blister rust. Our results underscore the importance of considering habitat attributes along with demographic parameters in sensitivity routines. GRIP 2.0 is an important 
40 decision-support tool that can be used to prioritize research, identify habitat-based thresholds and

41 management intervention points to improve probability of species persistence, and evaluate

42 trade-offs of alternative management options. 


\section{Introduction}

45 Addressing the realities and complexities of population-level responses to global change

46 increasingly requires the integration of multiple modeling approaches that capture changes in

47 habitat and climatic suitability and population dynamics, while accounting for the relationship

48 between the environment and demographics (Schurr et al., 2012). Population dynamics models

49 coupled with species distribution models (SDMs; Guisan \& Thuiller, 2005) is one modeling

50 framework that is used increasingly to quantify relative risks of extinction, and guide scientific

51 research and management decisions for rare or threatened species (Keith et al., 2008; Anderson

52 et al., 2009; Naujokaitis-Lewis et al., 2013). By capturing many of the key ecological processes

53 and mechanisms, coupled SDM-population dynamics models represent a powerful simulation-

54 based approach to predict the consequences of populations to dynamic future scenarios of land-

55 use and climate change (Franklin, 2010). Additionally, the explicit modeling of demographic

56 processes that directly relate to extinction risk addresses some of the challenges with

57 interpretation of SDM outcomes, where changes in area of suitable habitat are often simply

58 assumed to be linearly related to extinction risk (Thuiller et al., 2008; Fordham et al., 2012).

59 While the increasing realism of coupled SDM-population dynamics models is an

60 attractive feature, the reliance on extensive ecological and landscape data and multi-model

61 integrations results in complex models with many potential types and sources of uncertainty. Of

62 particular relevance, epistemic uncertainties, which include uncertainty related to natural

63 variation of ecological systems, model uncertainties (i.e. model specification), and parameter

64 uncertainties (Elith, Burgman \& Regan, 2002; Regan, Colyvan \& Burgman, 2002), are

65 associated with each of the sub-models, as well as the functions that link them. For example, in

66 the context of SDMs, various factors can affect model predictive power and the resultant spatial 
67 prediction outcomes, including the type of SDM algorithm and variables selected to model

68 habitat suitability (Barry \& Elith, 2006; Dormann et al., 2008), while the choice of thresholds to

69 distinguish suitable habitat from unsuitable areas can introduce further errors into maps (Liu,

70 White \& Newell, 2011). When the habitat map derived from the SDM forms the basis for

71 defining the spatial structure of a (meta-) population (i.e. number, size, shape, and location of

72 patches or populations), demographic parameters may be expressed as functions of map-based

73 habitat attributes. Subsequently, uncertainties associated with SDMs can propagate through to

74 predictions of (meta-) population trajectories and metrics including estimates of extinction risk.

75 The predictions from coupled SDM-population dynamics models are also influenced by

76 uncertainties associated with the specification of relationships and parameters used to model

77 demographic processes. Population models are often formulated with complex relationships,

78 which can introduce substantive uncertainties in expectations due to a combination of model

79 structure and parameter uncertainties (Reed et al., 2002; Naujokaitis-Lewis et al., 2009; Zurell et 80 al., 2011). .

Despite the advantages of coupled SDM-population dynamics models, it is important to

82 understand the potential propagation and influence of uncertainties resulting from each of the

83 sub-models to avoid a false sense of confidence in outcomes and identify management options

84 that are robust to those uncertainties. Sensitivity analyses are used to identify factors that

85 influence uncertainty in the predictions, identify research priorities for reducing uncertainty,

86 evaluate competing model structures, and compare the expected performance of alternative

87 management scenarios (Cross \& Beissinger, 2001; Saltelli et al., 2006). While extensive recent

88 efforts address uncertainties in SDMs when used independently (e.g., Dormann et al., 2008;

89 Buisson et al., 2010), evaluating uncertainties and their propagation through to coupled SDM- 
90 population dynamics model predictions is not consistently considered (Cabral et al., 2011; Zurell

91 et al., 2011; Prowse et al., 2016). Even the most commonly varied parameters in sensitivity

92 analyses of coupled SDM-population dynamics models, namely fecundities and survival rates,

93 are inconsistently assessed for their influence on model predictions (Naujokaitis-Lewis et al.,

94 2009). Performing sensitivity analyses that address the contribution of uncertainty across all sub-

95 models of a coupled or integrated model is an important step prior to applying complex

96 ecological models to address conservation problems.

Consideration of uncertainty associated with the whole model in a sensitivity analysis is not only a best practice, but may also help identify a broad range of influential parameters that can be manipulated in a management context. For example, while it is not possible to directly manipulate dispersal ability of a species per se as it is an intrinsic life-history trait, dispersal rates may be influenced by managing habitat features, such as the size of habitat patches and their configuration across the landscape. The potential influence of such factors are only likely to be revealed if these landscape-level habitat attributes are systematically varied in addition to demographic parameters in a sensitivity analysis (e.g., Naujokaitis-Lewis et al., 2013). Given that coupled SDM-population dynamics models are used to inform species and habitat recovery planning (Camaclang et al., 2014) exploring the influence of habitat structure in addition to

107 demographic rates in a sensitivity analysis may reveal insights into alternative factors that may be responsive to management actions.

In this paper we investigate the relative influence of uncertainty associated with habitat

110 and demographic parameters on model predictions for an endangered plant species by way of a

111 global sensitivity analysis (GSA). In a GSA the values of multiple parameters are varied

112 concurrently across their full parameter space, which represents their entire range of 
113 uncertainties and can account for interactions among parameters (Saltelli \& Annoni, 2010). To

114 achieve this objective, we developed GRIP 2.0, a novel decision-support tool that automates

115 GSAs of coupled SDM-population dynamics models. GRIP 2.0 extends the functionality of an

116 earlier version of this tool, GRIP 1.0 (Curtis \& Naujokaitis-Lewis, 2008). In addition to

117 evaluating the relative influence of uncertainty in demographic parameters associated with the

118 population dynamics model, GRIP 2.0 addresses uncertainty associated with the baseline habitat

119 maps (i.e, SDM predictive output). First, GRIP 2.0 can evaluate SDM-based uncertainties

120 associated with habitat maps derived from applying ensemble approaches whereby a number of

121 alternative models (e.g., based on different model algorithms) are fit and projected to explore a

122 range of outcomes (Araújo \& New, 2007). Second, if a single SDM was specified, the tool can

123 vary spatially-explicit habitat attributes including habitat suitability values and suitability

124 threshold values to convert maps to binary habitat vs non-habitat. Here, users can specify the

125 degree of spatial-autocorrelation among habitat suitability values. In both cases, it is possible to

126 vary the size and number of habitat patches in the GSA. These two approaches to varying SDM-

127 based uncertainties and habitat patches enable GRIP 2.0 applications to address both

128 macroecological and landscape-scale questions. By targeting multiple types of uncertainty

129 associated with model structure, parameters, and natural variation and stochasticity connected to

130 SDMs and population dynamics models, we capture dominant sources of variation in coupled

131 models (Naujokaitis-Lewis et al., 2009). We applied GRIP 2.0 to a published coupled model of

132 the threatened plant species, whitebark pine (Pinus albicaulis) (Ettl \& Cottone, 2004), as a proof

133 of concept to address our objective and to evaluate the application of this decision-support tool. 


\section{Methods}

\section{Whitebark pine coupled SDM-population dynamics model}

136 Whitebark pine is classified as an Endangered species (Mahalovich \& Stritch, 2013) in decline

137 primarily due to blister rust infections (Cronartium ribicola J.C. Fisch.), although the mountain

138 pine beetle (Dendroctonus ponderosae) epidemic and fire suppression are also major threats. The

139 original stochastic spatially-explicit metapopulation dynamics model was undertaken to evaluate

140 the influence of blister rust infection on whitebark pine viability and persistence in Mount

141 Rainier National Park, Washington, USA, where it is in danger of local extinction (Ettl \&

142 Cottone, 2004). As such, it is also referred to as a population viability analysis (PVA).

143 The whitebark pine model (Ettl \& Cottone, 2004) was implemented using RAMAS GIS

144 software (Akçakaya, 2002) and relied on the RAMAS Spatial module to identify populations (i.e.

145 habitat patches) using a raster-based habitat suitability map of a $420.3 \mathrm{~km}^{2}$ region in the park.

146 This population map provides the basis on which metapopulation dynamics are simulated in the

147 RAMAS Metapop module. A total of 46 populations were identified by the RAMAS patch

148 detection algorithm, which was consistent with the actual distribution of trees (Ettl \& Cottone,

149 2004). The authors used aerial photography to estimate initial abundances within each of the

150 populations. Vegetation plots were used to estimate the proportion of individuals in each of the

15113 stage classes and the final stage matrix included 24 transition probabilities that modeled both

152 healthy and trees infected with blister rust. The stage classes included four seedling stages,

153 saplings, infected saplings, non-reproductive adults, infected non-reproductive adults, healthy

154 adult trees (Class 1), and three adult stages with various degrees of blister rust infection (Classes

155 2-4; Table 1). Adults in Class 1 through 4, non-reproductive, and infected non-reproductive 
156 adults were affected by a ceiling model of density dependence.

157 Seed dispersal among pairs of populations was distance-dependent whereby dispersal rates

158 are calculated as a function of distance between populations and the parameters of the dispersal-

159 distance function of the original model. The general form of the model is:

160

$$
m_{i j}=a \times \exp \left(-D_{i j}^{c} / b\right)
$$

161 where $m_{i j}$ is the dispersal rate between the $i$ th and $j$ th populations, $a$ (scaling parameter), $b$, and $c$

162 are function parameters, and $D_{i j}$ is the distance between a pair of populations. The dispersal

163 distance function parameters for the whitebark pine model were $a=0.1, b=0.5, c=1$, and $D_{\max }$

$164=2.5 \mathrm{~km}$ (maximum dispersal distance).

165 Blister rust disease was modeled as a catastrophe where the probability of invasion of a site

166 corresponded to the average invasion time of 8 years. When blister rust occurs, healthy

167 individuals become infected, leading to declines in survival and fecundity rates. Specifically,

168 saplings, non-reproductive adults, and healthy adults (Class 1) transition to infected sapling,

169 infected non-reproductive adults, and Class 2 adult stage, respectively. Once sapling or non-

170 reproductive adult stages become infected, they continue on to death, while reproductive adult

171 stages cycle through to Class 4 , where fecundities are lower. The proportion of individuals that

172 transition into an infected class was based on empirical data and calibration tests in the original

173 model. The model includes both demographic and environmental stochasticity, with the latter

174 based on a lognormal distribution. A full description of the model is detailed in Ettl and Cottone 175 (2004) and stage classes are defined in Table 1.

176 RAMAS Spatial uses spatial data representing habitat requirements for a species, a user- 
177 defined habitat suitability function, and habitat-specific demographic relationships to derive

178 metapopulation structure (Akçakaya \& Root, 2005). The original study included a habitat

179 suitability map at a resolution of $0.02 \mathrm{~km}$ with suitability values ranging from 0 to 5 and a

180 threshold value of 1 was applied to distinguish between non-suitable and suitable habitat. We

181 estimated habitat-specific demographic relationships because these were not provided by the

182 authors. Using data available in the original whitebark pine PVA, we fit linear regression models

183 to define the relationships of total habitat suitability (ths, sum of habitat suitability values of all

184 raster cells belonging to a patch), to patch-specific initial abundances and carrying capacity,

185 separately. We used ths instead of habitat area as this incorporates a measure of habitat area

186 weighted by habitat quality. Our estimated relationship between ths and initial abundance was;

$$
\text { Initial abundance }=227.32 * \text { ths }
$$

with an $\mathrm{r}^{2}=0.780, p<0.01$. The relationship between ths and carrying capacity, $K$ was;

$$
K=0.8449 * t h s
$$

with an $\mathrm{r}^{2}=0.765, p<0.01$. Apart from standardizing the time horizon to 100 years and

191 extinction threshold to 0, and formatting the input files for use with GRIP 2.0 (see Appendix A)

192 the model was not further modified. We assumed that the remaining parameter values and model

193 structure synthesized the best available information.

\section{Overview of GRIP 2.0}

195 We created GRIP 2.0 in R (Generating Random Input Parameters; developed and tested in v.

196 2.7.1 through 3.2.1 (R Core Team, 2015), which interacts with RAMAS Spatial and Metapop,

197 two modules of the software RAMAS GIS (Akçakaya \& Root, 2005), and uses R-spatial 
198 packages to facilitate spatial and geostatistical analyses. There are two versions available, each

199 compatible with a one of RAMAS GIS v 5.0 or $v$ 6.0. GRIP 2.0 builds on GRIP 1.0 (Curtis \&

200 Naujokaitis-Lewis, 2008) and uses Monte Carlo methods to vary parameters (1) directly on the

201 grid-based habitat suitability map used as an input to RAMAS Spatial, (2) specified in the

202 RAMAS Spatial module, and (3) specified in the RAMAS Metapop module (Figure 1). Unique

203 sets of input parameters for the Spatial and Metapop modules of RAMAS GIS are drawn from

204 user-defined random distributions reflecting parameter uncertainty and the range of plausible 205 values.

Once the replicate landscapes and corresponding metapopulation models are defined, GRIP

2.0 runs the replicate simulations in batch mode, and collates the input parameter values and predictions into a comma delimited file for subsequent analyses. Thus, GRIP 2.0 automates the generation of unique sets of replicate stochastic simulation files and manages the simulations with batch files, which would otherwise be prohibitive if undertaken manually (McCarthy,

211 Burgman \& Ferson, 1995). The code of this global sensitivity analysis program is annotated and

212 easily customized to reflect a particular species' biology or address related research questions. In

213 the following sections, we briefly describe how habitat attributes and demographic parameters

214 are varied in GRIP 2.0, but details are also annotated in Appendix A and the landscape generator

215 and routine for varying demographic parameters is described in more detail in Appendix B.

\section{Generation of alternative landscapes}

217 GRIP 2.0 generates alternative landscapes by varying the number of patches (i.e. populations;

218 herein we use the terms patch and population interchangeably), patch size, and the habitat

219 suitability value associated with each raster spatial data cell directly on the original habitat 
220 suitability and patch maps (Table 1). The current version of GRIP 2.0 includes four options for

221 varying habitat suitability maps: 'random.normal', 'spatially autocorrelated', 'ensemble', and 'no

222 variation' (Table 1). In the 'random.normal' option, habitat suitability (HS) values are simulated

223 by drawing a value for each grid cell from a normal distribution based on the mean and standard

224 deviation of HS values within the reference landscape. There is no spatial autocorrelation

225 amongst habitat suitability values. The 'spatially autocorrelated' option provides flexibility to

226 vary the degree of autocorrelation among HS values simulated using the RandomFields R

227 package (Schlather et al., 2015). Base settings include a Gaussian model of spatial

228 autocorrelation with a mean of 0 , variance of 5 , nugget value of 1 , and a scale of 10 , creating a

229 generally highly correlated surface. All HS values are set to be equal to or greater than the newly

230 sampled HS threshold value (see below). The 'ensemble' approach can evaluate SDM-based

231 uncertainties associated with alternative models (e.g., based on different model algorithms)

232 whereby a number of models are fit (an ensemble) and then combined into a consensus

233 prediction. In GRIP 2.0, users must include a raster-based ensemble SDM prediction layer

234 reflecting a consensus estimate of habitat suitability and a raster reflecting uncertainties in that

235 prediction. The sensitivity analysis of habitat suitability thus reflects cell-based uncertainty in the

236 prediction and captures error propagation across multiple SDMs. Finally, the 'no variation'

237 option ensures that HS is not included in the GSA. Given information contained in the original

238 model, we varied HS for the whitebark pine based on the 'random.normal' option.

Additionally, two user-specified settings in RAMAS Spatial that inform its patch

240 detection algorithm were varied: the habitat suitability threshold, which is used to distinguish

241 between unsuitable and suitable cells, and the neighbourhood distance value, used to identify

242 spatially discrete patches of suitable habitat. For further details see Table 1. 


\section{Variation of demographic parameters}

244 GRIP 2.0 generates unique replicate metapopulation models (one for each replicate landscape

245 model) by varying parameters specified in RAMAS Metapop. A total of 23 demographic

246 parameters specified in the whitebark pine metapopulation model were varied in the GSA (Table

247 1). These included stage-specific survival and fecundity rates, dispersal rates, dispersal survival,

248 correlation of vital rates among populations, and catastrophe parameters. All demographic

249 parameters were varied using sampling distributions and parameter ranges as specified in GRIP

250 1.0, a version of this freeware developed for spatial PVAs that are not based on spatially-explicit

251 maps of habitat or habitat suitability (Curtis \& Naujokaitis-Lewis, 2008). We did not vary the

252 model of density dependence to retain the original model structure to the extent possible. Further

253 details governing the sampling distributions, mean and measure of variation for each parameter

254 varied in the GSA are described in Table 1 and Appendix B. As with other parameters not varied

255 in this version of GRIP 2.0, the code is extensively annotated and customizable. To the extent

256 possible, we used information from the original model to select biologically relevant uncertainty

257 estimates, and in the case where these were not specified we either applied a 10\% coefficient of

258 variation or sampled from a uniform distribution (Table 1). While this $10 \%$ value is somewhat

259 arbitrary, we used the best available information to select realistic uncertainty estimates. Users

260 are able to modify these ranges, and even sampling distributions to better reflect the research and

261 management context of their study system.

\section{Simulations and data analysis}

263 Using the whitebark pine map as the original reference landscape, we created a total of 10,000

264 replicates, where refers to the total number of final model configurations that includes variation 
265 in landscape/habitat suitability parameters (Figure 2), as well as demographic parameters. Each

266 of the replicate metapopulation dynamics models consisted of 1000 stochastic runs using a 100

267 year time period. For each replicate landscape file, we calculated landscape composition and

268 configuration metrics using RAMAS GIS. The landscape metrics included number of patches,

269 total amount of suitable habitat (an integrated measure of both habitat amount and suitability),

270 mean patch area, edge to area ratio, and connectivity, calculated as the proportion of all

271 population pairs that are linked through dispersal. A full description of the landscape metrics

272 calculated by RAMAS GIS and associated mathematical formulae is available in Akçakaya and $273 \operatorname{Root}(2005)$.

We applied a boosted regression tree (BRT) to rank the relative influence of habitat-

275 based measures of landscape pattern and demographic parameters on the binary response

276 variable, conservation status. Conservation status was calculated based on the probability of

277 extinction over a 100-year time period with 0.1 defined as the threshold for distinguishing

278 metapopulations expected to be not at risk from those expected to be at risk of extinction. This

279 benchmark corresponds to international criterion for listing species as Vulnerable (Criterion E;

280 IUCN, 2001). We used the machine-learning method of BRTs based on our interest in

281 understanding the relative importance of different parameter uncertainties on model outcomes

282 and additional flexibilities of BRT for our analysis purposes (De'ath, 2007; Elith et al., 2008).

283 GRIP 2.0 provides the means to generate and propagate uncertainties while decisions regarding

284 how to analyze such outcomes are flexible, with BRT representing one option. The BRT

285 functionality was not coded into GRIP 2.0 but was a supplemental statistical analysis performed

286 once all replicate simulations were created and run using GRIP 2.0 and RAMAS. 
We specified a binomial error structure and link function and used untransformed data in

288 the BRT as it does not require data transformations (Elith et al., 2008). We applied a tree

289 complexity $(t c)$ value of 2 , which fits the BRT with up to two-way interactions. Learning rate

290 (lr), which determines the contribution of each tree as it is added to the model, was specified at a

291 value of 0.01 , which was optimized to ensure a minimum of 1000 trees were fit for the model

292 (Elith et al., 2008). Prediction accuracy was measured using the percent deviance explained by

293 the model, which measures the goodness of fit between the prediction and observed values. The

294 relative influence of each predictor variable was assessed by calculating its contribution to

295 reducing the overall model deviance of the BRT model. We identified important modeled

296 interactions by quantifying the strength of pairwise interactions while keeping non-focal

297 variables at their mean values. The BRT model, including relative influence of predictors, and

298 evaluation and visualization of two-way interactions were performed in R (R Core Team, 2015)

299 using the 'gbm' package (Ridgeway, 2015) and functions available in Elith et al, (2008).

300 Results

301 Influential parameters on whitebark pine conservation status

302 The baseline model of the whitebark pine in the presence of blister rust predicts a dramatic

303 decline of the metapopulation in Mt. Rainier National Park (Ettl \& Cottone, 2004). The two-way

304 interaction BRT model resulted in a high level of explanatory power. The model accounted for

$30590 \%$ of the mean total deviance (1 - mean residual deviance / mean total deviance; 1 -

306 0.014/0.137). For the 2-way interaction BRT model, the loss function was minimized at 4250

307 trees, and the model was optimized with a learning rate of 0.01 and a bag fraction of 0.05 . The 
308 five most important variables based on the BRT included total habitat amount (40.3\%), survival

309 class 4 (13.7\%), survival class 3a (12.8\%), catastrophe intensity (8.9\%), and mean carrying

310 capacity per patch $(6.6 \%)$ (Table 2$)$.

311 The partial dependence plots in Figure 3 illustrate the relationship between the four most

312 important variables and conservation status after accounting for the average effect of all other

313 variables. These plots suggest that a conservation status of 'Vulnerable' is a function of low

314 amounts of total habitat in the landscape, low survival rates of trees in classes $3 \mathrm{a}$ and 4 , and

315 stronger negative effects of catastrophes (i.e. blister rust).

\section{Importance of interactions}

317 The BRT analysis identified a number of strong interactions influencing whitebark pine

318 conservation status. The strongest interaction was between total habitat amount and survival rate

319 of trees in class 4 (Figure 4A). Specifically, extinction risk increases more rapidly for lower

320 values of survival and lower amounts of habitat in the landscape, but as survival increases above

3210.8 , less amount of habitat is required for the conservation status to remain 'not-at-risk'. Based

322 on the second most important interaction, the influence of catastrophe intensity on extinction

323 probability is conditional on the total amount of habitat in the landscape (Figure 4B). In other

324 words, when the effect of catastrophes is weaker, less amount of habitat is needed for the

325 predicted status to remain not-at-risk whereas when catastrophes have a larger effect more

326 habitat is needed to buffer the risk status rank. Both of these interactions demonstrate the

327 importance of habitat amount in mediating the negative effects of blister rust on whitebark pine

328 extinction risk within this landscape. 


\section{Habitat thresholds}

330 Based on qualitative assessments, the 3-dimensional plots revealed thresholds in habitat-based

331 features. For the two strongest interactions (Figure 4), across all survival rates and catastrophe

332 intensity values, below total habitat amounts of $2 \mathrm{~km}^{2}$ the predicted risk of extinction increases

333 more steeply. Despite the strong interaction among these pairs of variables, this suggests the

334 existence of thresholds in total habitat amount for the Mount Rainier whitebark pine

335 metapopulation infected with blister rust. As the number of populations did not interact strongly

336 with other demographic parameters or habitat features, the partial dependence plots may be

337 interpreted directly: thresholds were evident for the number of populations where conserving >

33820 populations resulted in predicted conservation status of 'not-at-risk', based on international

339 listing criteria.

\section{Discussion}

341 The use of coupled SDM-population dynamics models that relate land-use and climate

342 dynamics to population-level demographic parameters present large potential applications for

343 endangered species recovery and habitat planning. However, the potential for the propagation of

344 errors and uncertainties throughout the modeling process represents a true concern. We

345 developed a novel tool to illustrate the importance of advancing the application of global

346 sensitivity analyses to targeting each component model of coupled SDM-population models.

347 Based on the whitebark pine model, the most important variables on predictive outcomes

348 included a combination of demographic and landscape habitat features. The inclusion of habitat

349 features in a sensitivity analysis broadens the scope of potentially effective management actions

350 aimed at supporting persistence of endangered species beyond the usual focus on vital rates. 
351 Such assessments are fundamental not only to help identify parameters requiring further data

352 collection to reduce model uncertainty but also for evaluating and prioritizing costly habitat-

353 based management recommendations for endangered species.

354 Simulating alternative realizations of landscape and habitat structure

355 Landscape level experiments involving adequate replication are often difficult to implement due

356 to issues of scale. Consequently, experimentation by simulation using landscape generators

357 presents a viable alternative to develop a better understanding of the relationship between

358 landscape pattern and process (Gardner \& Urban, 2007), predict species response to landscape

359 change (Tischendorf, 2001), and more generally to develop and test hypotheses. Because GRIP

3602.0 modifies an existing reference landscape, certain landscape elements, such as size and shape

361 of some patches, are retained in replicate simulations. This leads to more realistic simulated

362 landscapes, unlike neutral or multi-fractal models (With \& Crist, 1995). Although not applied to

363 the whitebark pine model, GRIP 2.0 allows users to include a landscape mask, enabling habitat

364 creation only in those regions outside of the mask. This aspect increases the functionality GRIP

3652.0 and the realism of its outputs; a mask may contain intractable barriers to habitat creation,

366 such as roads, representing landscape constraints that many analysts and managers must contend 367 with.

368 Replicate landscapes produced by GRIP 2.0 represented a wide range of landscape structural

369 variation allowing an evaluation of the influence of a broad range of structural attributes on

370 extinction probability of whitebark pine, and by the same token, a broad range of scenarios to

371 explore for conservation and management planning. By using Monte Carlo simulations,

372 landscape features modified included the amount of habitat, patch sizes, or the degree and 
373 directionality of spatial autocorrelation in replicate landscapes. Such flexibility is important

374 given simulation studies and our results that have identified thresholds related to levels of

375 habitat within a landscape below which species viability rapidly declines (Swift \& Hannon,

376 2010). The GRIP 2.0 code is highly annotated allowing users to understand, scrutinize, and

377 modify the code to reflect a particular species' biology, sampling distributions, or landscape

378 dynamics.

379 The original whitebark pine model did not model consequences of climate change on future

380 projections. Thus our implementation of GRIP 2.0 to the whitebark pine model does not address

381 uncertainty in spatio-temporal projections of habitat suitability under future climate change

382 associated with selection of General Circulation Models, for example. However, this is not an

383 inherent limitation of the tool as GRIP 2.0 can be modified to integrate this additional source of

384 uncertainty as in Naujokaitis-Lewis et al. (2013). Additionally, while we did not explicitly

385 address uncertainty in the habitat-demographic relationship, our GSA approach implicitly

386 addresses this source of variation by varying population-specific initial abundances and carrying

387 capacities. Should models incorporate temporal trends in vital rates associated with estimated

388 habitat-demographic relationships, GRIP 2.0 is customizable to reflect this potential source of

389 variation.

\section{The relative influence of parameters and their interactions}

391 By varying multiple parameters simultaneously using probability distribution functions to

392 represent the plausible range of parameter values, GRIP 2.0 performs a global sensitivity

393 analysis, in which parameters are varied concurrently over the plausible range of parameter space

394 (Saltelli et al., 2006). Varying habitat features associated with habitat suitability maps, such as 
395 habitat amount, habitat suitability, and number of patches enabled a comparison of the relative

396 influence of habitat-based attributes on whitebark pine meta-population dynamics relative to

397 demographic parameters. Outcomes of our global sensitivity analyses indicated that both

398 demographic and habitat factors influence predictions of whitebark pine persistence. Our GSA

399 identified different influential parameters from the original study, which did not vary habitat-

400 based factors (Ettl \& Cottone, 2004). Based on the predicted trajectories of individual whitebark

401 pine subpopulations over time, Ettl and Cottone (2004) concluded that size and distribution of

402 subpopulations influenced the trajectory of individual populations. The authors also concluded

403 that the model was more sensitive to changes in the vital rates of healthy trees than infected trees,

404 and less sensitive to changes in the vital rates of mature trees than of younger trees, and more

405 sensitive to the frequency of invasion than by the effect of blister rust on vital rates. Without

406 applying a GSA, however, the authors were not able to rank the relative influences of these

407 factors on the dynamics of the meta-population as a whole, or identify key interactions among

408 parameters and thresholds that could be used to inform management decisions. By contrast, the

409 results of our GSA indicated that model predictions were more sensitive to older stage classes

410 that were also infected by blister rust disease. We also identified certain habitat variables as

411 highly influential, which broadens the range of information that can be used to develop effective

412 management actions. Our simulations were standardized to 100 years (as per criterion E for

413 IUCN species assessments), but with poor recruitment/low survival, this metapopulation may be

414 at greater risk over the longer term (Ettl \& Cottone, 2004).

415 The relatively high rank of certain habitat factors, such as total amount of habitat, highlights

416 the importance of spatial habitat-based landscape features as important drivers of whitebark pine

417 persistence as a way to mediate the negative consequences of blister rust disease. Spread of the 
418 fungal blister rust pathogens is complex; blister rust has a five-stage life cycle and requires two

419 hosts, whitebark pine (or any other five-needled pines) and any species in the genus Ribes.

420 Predicting the spread of the blister rust through the distribution of whitebark pine individuals and

421 populations is difficult as the pathogen spreads from Ribes hosts to whitebark pine via wind-

422 borne spores, and not from tree to tree (McDonald \& Hoff, 2001). Although the original PVA

423 model does not explicitly model transmission through Ribes, the outcomes of our GSA indicate

424 that managing habitat parameters could help offset declines in abundance related to blister rust.

425 Given that proximity to Ribes species contributes to increased rates of blister rust infection

426 (Smith et al., 2011), future research that explicitly explores the spatial context of Ribes' role in

427 disease transmission dynamics would improve our understanding of the role of multiple

428 interacting parameters that influence whitebark pine persistence.

\section{Thresholds and conservation implications}

430 Theoretical models have been used to generate hypotheses, such as the nonlinear threshold

431 hypothesis, which predicts that species exhibit threshold responses due to the increasing

432 influence of fragmentation below a certain amount of habitat (Andrén, 1994) Although

433 theoretical models predict that below critical threshold points, increased fragmentation results in

434 lowered colonization success and increased extinction probability (With \& King, 1999),

435 empirical validation of such responses are uncommon (Fahrig, 2003). Our results corroborate the

436 occurrence of thresholds in response to declines in both habitat amount and quality. Visual

437 assessment of bivariate plots of probability of extinction as a function of landscape variables

438 indicated the presence of thresholds as evidenced by strong negative exponential decay curves

439 (results not shown). Although we did not quantitatively derive threshold points for whitebark 
440 pine, these roughly translate to 20 populations, a mean connected distance of approximately 5

$441 \mathrm{~km}$, an average habitat suitability of 2.3 per patch, and a mean patch size of $\sim 0.35 \mathrm{~km}^{2}$. Further

442 insights into the behavior and occurrence of thresholds in real settings may help identify

443 conservation strategies that specify minimum patch size targets, or provide guidance related to

444 landscape level measures, such as habitat amount (Betts, Forbes \& Diamond, 2007).

\section{Conclusions}

446 Understanding the relative importance of factors influencing species extinction risk can

447 provide information needed for the design of actions to target species recovery and persistence.

448 Our approach provides one way to assess the role of uncertainty of multiple parameters on

449 species persistence, and assist in the prioritization of research and evaluation of alternative

450 management strategies (Guisan et al., 2013). In this particular case, we have shown that for a

451 species threatened by disease invasion, both demographic and habitat-based variables rank high

452 in terms of influence on the risk of extinction. This suggests that there are multiple options for

453 effective management of whitebark pine, ranging from direct actions targeting diseased

454 individuals or mediation through habitat-based measure. However, the relative influence of such

455 options only becomes apparent through their explicit inclusion in a global sensitivity analysis

456 and subsequent assessment via an appropriate analysis, such as a BRT as applied in this example.

457 Furthermore, a global sensitivity analysis framework is considered a best practice that can be

458 incorporated into the development and communication of PVAs (Pe'er et al., 2013). Future work

459 using coupled SDM-population dynamics models to prioritize research and evaluate management

460 strategies would benefit from the integration of a decision-theory approach and socio-economic

461 information to help inform investments required to achieve specified conservation objectives. 


\section{Acknowledgements}

463 We thank Roger Bivand and Adrian Baddeley who helped with our various programming

464 queries, Norm Hodges and Sarah Gergel for assisting with computer support, R. Akçakaya who

465 fielded numerous technical questions related to RAMAS GIS, and Peter Arcese, Jordan

466 Rosenfeld, and Pippa Shepherd for useful discussions. We thank the anonymous reviewers for

467 comments on previous versions.

468

469

\section{References}

470

471

472

473

474

475

476

477

478

479

480

Akçakaya HR. 2002. RAMAS GIS: Linking landscape data with population viability analysis (version 4.0). Setauket, New York: Applied Biomathematics.

Akçakaya HR., Root WT. 2005. RAMAS GIS: Linking Spatial Data with Population Viability Analysis, version 5.0. New York: Applied Biomathematics.

Anderson BJ., Akçakaya HR., Araújo MB., Fordham DA., Martinez-Meyer E., Thuiller W., Brook BW. 2009. Dynamics of range margins for metapopulations under climate change. Proceedings. Biological sciences / The Royal Society 276:1415-1420. DOI: 10.1098/rspb.2008.1681.

Andrén H. 1994. Effects of habitat fragmentation on birds and mammals in landscapes with different proportions of suitable habitat: a review. Oikos 71:355-366.

Araújo MB., New M. 2007. Ensemble forecasting of species distributions. Trends in Ecology 
482

483

484

485

486

487

488

489

490

491

492

493

494

495

496

497

498

499

500

Barry S., Elith J. 2006. Error and uncertainty and habitat models. Journal of Applied Ecology 43:413-423.

Betts MG., Forbes GJ., Diamond AW. 2007. Thresholds in songbird occurrence in relation to landscape structure. Conservation Biology 21:1046-1058. DOI: 10.1111/j.1523-

Buisson L., Thuiller W., Casajus N., Lek S., Grenouillet G. 2010. Uncertainty in ensemble 1739.2007.00723.x.

Cabral JS., Bond WJ., Midgley GF., Rebelo AG., Thuiller W., Schurr FM. 2011. Effects of forecasting of species distribution. Global Change Biology 16:1145-1157. DOI: 10.1111/j.1365-2486.2009.02000.x. Harvesting Flowers from Shrubs on the Persistence and Abundance of Wild Shrub Populations at Multiple Spatial Extents. Conservation Biology 25:73-84. DOI: 10.1111/j.1523-1739.2010.01628.x.

Camaclang AE., Maron M., Martin TG., Possingham HP. 2014. Current practices in the identification of critical habitat for threatened species. Conservation Biology 00:n/a-n/a. DOI: $10.1111 /$ cobi.12428.

Cross PC., Beissinger SR. 2001. Using logistic regression to analyze the sensitivity of PVA models: a comparison of methods based on African wild dog models. Conservation Biology $15: 1335-1346$.

Curtis JMR., Naujokaitis-Lewis I. 2008. Sensitivity of population viability to spatial and 

nonspatial parameters using grip. Ecological Applications 18:1002-1013.

502 De'ath G. 2007. Boosted regression trees for ecological modeling and prediction. Ecology 88:243-251. DOI: 10.1890/0012-9658(2007)88[243:BTFEMA]2.0.CO;2.

504 Dormann CF., Purschke O., Garcia Marquez JR., Lautenbach S., Schroder B. 2008. Components 505 of uncertaintyin species distribution analysis: a case study of the great greyshrike. Ecology $506 \quad 89: 3371-3386$.

507

508

509

510

511

512

513

514

515

516

517

518

519

520

Elith J., Leathwick JR., Hastie T., R. Leathwick J. 2008. Elith, Leathwick \& Hastie A working guide to boosted regression trees - Online Appendices Page 1. Journal of Animal Ecology 77:802-13. DOI: 10.1111/j.1365-2656.2008.01390.x.

Elith J., Burgman MA., Regan HM. 2002. Mapping epistemic uncertainties and vague concepts in predictions of species distribution. Ecological Modelling 157:313-329. DOI: 10.1016/S0304-3800(02)00202-8.

Ettl GJ., Cottone N. 2004. Whitebark Pine (Pinus albicaulis) in Mt . Rainier National Park, USA: Response to Blister Rust infection. In: Akçakaya HR, Burgman MA, Kindvall O, Wood C, Sjögren-Gulve P, Hatfield J, McCarthy MA eds. Species Conservation and Management: Case Studies. Oxford University Press, 36-47.

Fahrig L. 2003. Effects of Habitat Fragmentation on Biodiversity. Annual Review of Ecology, Evolution, and Systematics 34:487-515. DOI: 10.1146/annurev.ecolsys.34.011802.132419.

Fordham DA., Resit Akçakaya H., Araújo MB., Elith J., Keith DA., Pearson R., Auld TD., Mellin C., Morgan JW., Regan TJ., Tozer M., Watts MJ., White M., Wintle BA., Yates C., 
521 Brook BW. 2012. Plant extinction risk under climate change: Are forecast range shifts alone

522 a good indicator of species vulnerability to global warming? Global Change Biology

523 18:1357-1371. DOI: 10.1111/j.1365-2486.2011.02614.x.

524 Franklin J. 2010. Moving beyond static species distribution models in support of conservation 525 biogeography. Diversity and Distributions 16:321-330. DOI: 10.1111/j.1472$526 \quad 4642.2010 .00641 . x$

527 Gardner RH., Urban DL. 2007. Neutral models for testing landscape hypotheses. Landscape $528 \quad$ Ecology 22:15-29.

529 Guisan A., Tingley R., Baumgartner JB., Naujokaitis-Lewis I., Sutcliffe PR., Tulloch AIT., 530 Regan TJ., Brotons L., Mcdonald-Madden E., Mantyka-Pringle C., Martin TG., Rhodes JR., 531 Maggini R., Setterfield S a., Elith J., Schwartz MW., Wintle B a., Broennimann O., Austin 532 M., Ferrier S., Kearney MR., Possingham HP., Buckley YM. 2013. Predicting species 533 distributions for conservation decisions. Ecology Letters 16:1424-1435. DOI: $534 \quad 10.1111 /$ ele.12189.

535 Guisan A., Thuiller W. 2005. Predicting species distribution: Offering more than simple habitat 536 models. Ecology Letters 8:993-1009. DOI: 10.1111/j.1461-0248.2005.00792.x.

537 IUCN. 2001. IUCN Red List of threatened species categories and criteria, version 3.1. Gland, $538 \quad$ Switzerland.

539 Keith D., Akçakaya HR., Thuiller W., Midgley GF., Pearson RG., Phillips SJ., Regan HM., 540 Araújo MB., Rebelo TG. 2008. Predicting extinction risks under climate change: coupling 541 stochastic population models with dynamic bioclimatic habitat models. Biology letters 
543 Liu C., White M., Newell G. 2011. Measuring and comparing the accuracy of species

544 distribution models with presence-absence data. Ecography 34:232-243. DOI: 10.1111/j.1600-0587.2010.06354.x.

546

547

548

549

550

551

552

553

554

555

556

557

558

559

560

561

Mahalovich M., Stritch L. 2013.Pinus albicaulis. The IUCN Red List of Threatened Species 2013: e.T39049A2885918. Available at http://dx.doi.org/10.2305/IUCN.UK.20131.RLTS.T39049A2885918.en. (accessed December 8, 2015).

McCarthy MA., Burgman MA., Ferson S. 1995. Sensitivity analysis for models of population viability. Biological Conservation 73:93-100.

McDonald GI., Hoff RJ. 2001. Blister rust: an introduced plague. In: Tomback DF, Arno SF, Keane RE eds. Whitebark Pine Communities: Ecology and Restoration. Washington, D.C: Island Press, 193-220.

Naujokaitis-Lewis I., Curtis JMR., Arcese P., Rosenfeld J. 2009. Sensitivity analyses of spatial population viability analysis models for species at risk and habitat conservation planning. Conservation Biology 23:225-229.

Naujokaitis-Lewis IR., Curtis JMR., Tischendorf L., Badzinski D., Lindsay K., Fortin MJ. 2013. Uncertainties in coupled species distribution-metapopulation dynamics models for risk assessments under climate change. Diversity and Distributions 19:541-554. DOI: 10.1111/ddi.12063. 
562 JMR., Naujokaitis-Lewis I., Wintle BA., Henle K. 2013. A protocol for better design, 563 application, and communication of population viability analyses. Conservation Biology $564 \quad 27: 644-656$.

565 Prowse TAA., Bradshaw CJA., Delean S., Cassey P., Lacy RC., Wells K., Aiello-lammens ME., 566 Akçakaya HR., Brook BW. 2016. An efficient protocol for the global sensitivity analysis of 567 stochastic ecological models. Ecosphere 7:1-17. DOI: e01238. 10.1002/ecs2.1238.

568 R Core Team. 2015. R: A language and environment for statistical computing.

569 Reed JM., Mills LS., Dunning J.B. J., Menges ES., McKelvey KS., Frye R., Beissinger SR., 570 Anstett MC., Miller P. 2002. Emerging issues in population viability analysis. Conservation 571 Biology 16:7-19.

Regan HM., Colyvan M., Burgman MA. 2002. A taxonomy and treatment of uncertainty for 573 ecology and conservation biology. Ecological Applications 12:618-628.

Ridgeway G. 2015. gbm: Generalized Boosted Regression Models. R package version 2.1.1.

Saltelli A., Ratto M., Tarantola S., Campolongo M. 2006. Sensitivity analysis practices: strategies for model-based inference. Reliability Engineering and System Safety 91:11091125 .

Saltelli A., Annoni P. 2010. How to avoid a perfunctory sensitivity analysis. Environmental Modelling \& Software 25:1508-1517.

Schlather M., Malinowski A., Menck PJ., Oesting M., Strokorb K. 2015. Analysis, Simulation and Prediction of Multivariate Random Fields with Package RandomFields. Journal of 
583 Schurr FM., Pagel J., Cabral JS., Groeneveld J., Bykova O., O’Hara RB., Hartig F., Kissling 584 WD., Linder HP., Midgley GF., Schröder B., Singer A., Zimmermann NE. 2012. How to

585 understand species' niches and range dynamics: a demographic research agenda for 586 biogeography. Journal of Biogeography 39:2146-2162. DOI: 10.1111/j.13652699.2012.02737.x.

588

589

590

591

592

593

594

595

596

597

598

599

600

601

Smith EK., Resler LM., Vance E V., Carstensen Jr. LW., N. Kolivras KN. 2011. Blister rust incidence in treeline whitebark pine, Glacier National Park, U.S.A.: environmental and topographic influences. Arctic, Antarctic, and Alpine Research 43:107-117.

Swift TL., Hannon SJ. 2010. Critical thresholds associated with habitat loss: a review of the concepts, evidence, and applications. Biological reviews of the Cambridge Philosophical Society 85:35-53. DOI: 10.1111/j.1469-185X.2009.00093.x.

Thuiller W., Albert C., Araújo MB., Berry PM., Cabeza M., Guisan A., Hickler T., Midgley GF., Paterson J., Schurr FM., Sykes MT., Zimmermann NE. 2008. Predicting global change impacts on plant species' distributions: Future challenges. Perspectives in Plant Ecology, Evolution and Systematics 9:137-152. DOI: 10.1016/j.ppees.2007.09.004.

Tischendorf L. 2001. Can landscape indices predict ecological processes consistently? Landscape Ecology 16:235-254. DOI: 10.1023/A:1011112719782.

With KA., Crist TO. 1995. Critical thresholds in species' responses to landscape structure. Ecology 76:2446-2459. 
602 With KA., King AW. 1999. Extinction thresholds for species in fractal landscapes. Conservation $603 \quad$ Biology 13:314-326.

604 Zurell D., Grimm V., Rossmanith E., Zbinden N., Zimmermann NE., Schröder B. 2011.

605 Uncertainty in predictions of range dynamics: black grouse climbing the Swiss Alps.

$606 \quad$ Ecography 34:1-14. 
608 Figure Captions

609 Figure 1. Schematic of the GRIP 2.0 program for evaluating the sensitivity of habitat and

610 demographic parameter uncertainty and the generation of alternative landscapes on extinction

611 risk for metapopulation models created and simulated using RAMAS GIS. Parameters varied by

612 GRIP 2.0 are indicated by a dashed rectangle, model steps by a rectangle, and outputs by a

613 rounded rectangle.

614

615 Figure 2. The original $25.32 \mathrm{~km}$ x $16.6 \mathrm{~km}$ landscape map for whitebark pine (modified from Ettl

616 and Cottone 2004) includes 46 patches (A), and three of the simulated landscape maps (B-D)

617 created using GRIP 2.0 includes 10, 43, and 83 patches, respectively. Of the original patches

618 remaining in landscapes $\mathrm{B}$ and $\mathrm{D}$, all patches have decreased in size, while the original patches

619 remaining in landscape $\mathrm{C}$ have increased. Overall, the extent of the landscape for each replicate

620 simulation remains constant but composition, configuration, and habitat suitability values have

621 changed. For ease of representation, the landscape is depicted in a binary format where suitable

622 habitat is black and unsuitable habitat is white. New patches created by the GRIP 2.0 landscape

623 generator are assumed to be approximately circular in shape to take advantage of existing

624 functionality of R-spatial packages, but users could customize the code to create patches with

625 different sizes and shapes.

626

627 
628 Figure 3. Partial dependence plots for the four most important predictors of whitebark pine

629 extinction probability. Extinction probability is expressed on the logit scale.

630

631 Figure 4. Three-dimensional partial dependence plots for the two strongest interactions based on 632 a global sensitivity analysis of the whitebark pine metapopulation model. Parameters not plotted 633 remain at their mean value. a) Interaction between total habitat $\left(\mathrm{km}^{2}\right)$ amount and survival class

634 4, and b) interaction between total habitat amount and catastrophe intensity. Note, the total

635 habitat amount axis is truncated to a maximum value of $3 \mathrm{~km}^{2}$ as parameter combinations above 636 this value did not result in substantial variation in extinction probability. 
638 Appendices

639 Appendix A: GRIP 2.0 Annotated code

640 Appendix B: Details of GRIP 2.0 Landscape Generator and Sensitivity Analysis Protocol

641 
Figure 1 (on next page)

Flowchart of global sensitivity analysis program GRIP 2.0 


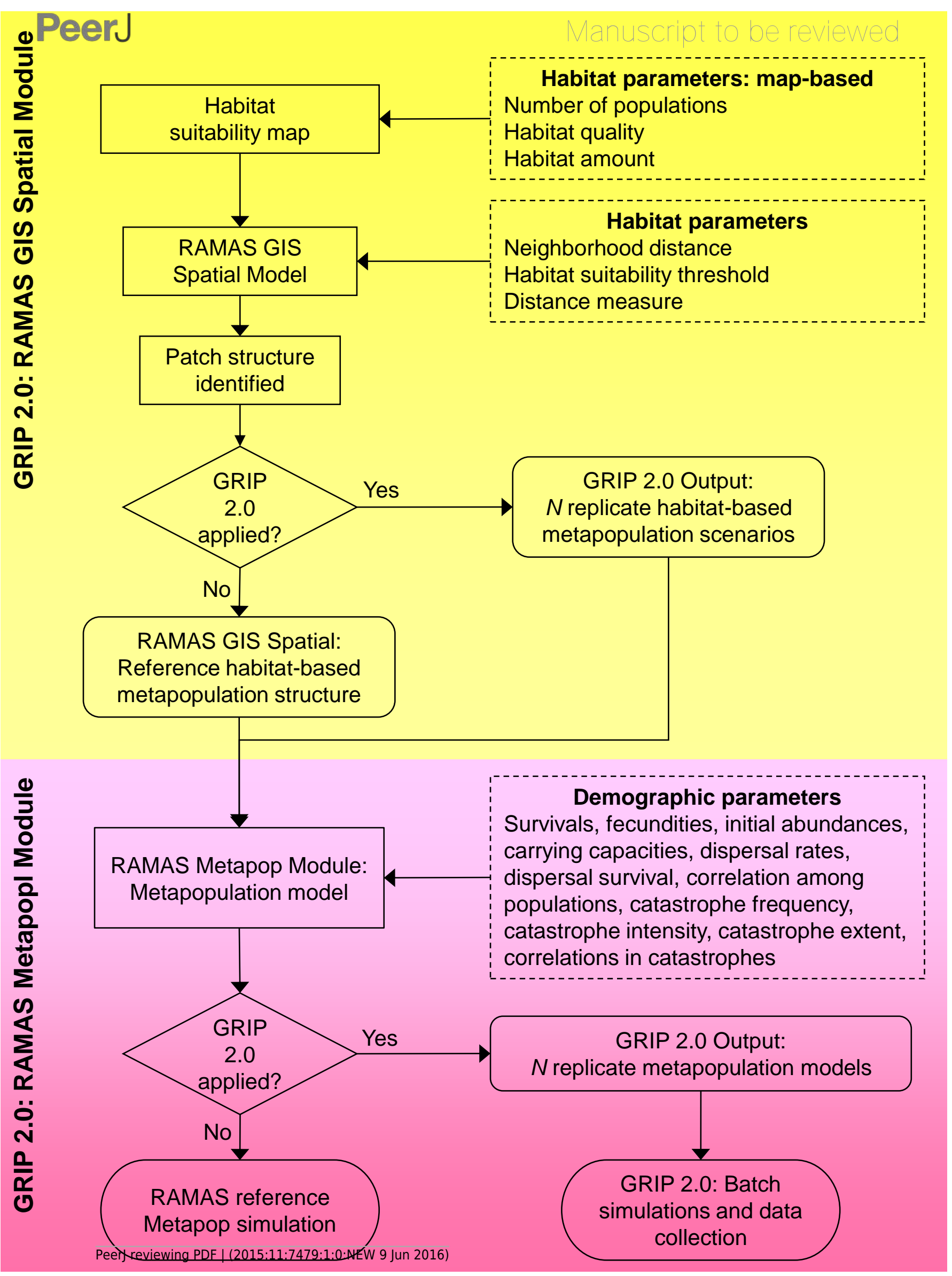




\section{Figure 2 (on next page)}

Examples of dynamic simulated landscapes based on original whitebark pine suitability model 
B Manuscript to be reviewed

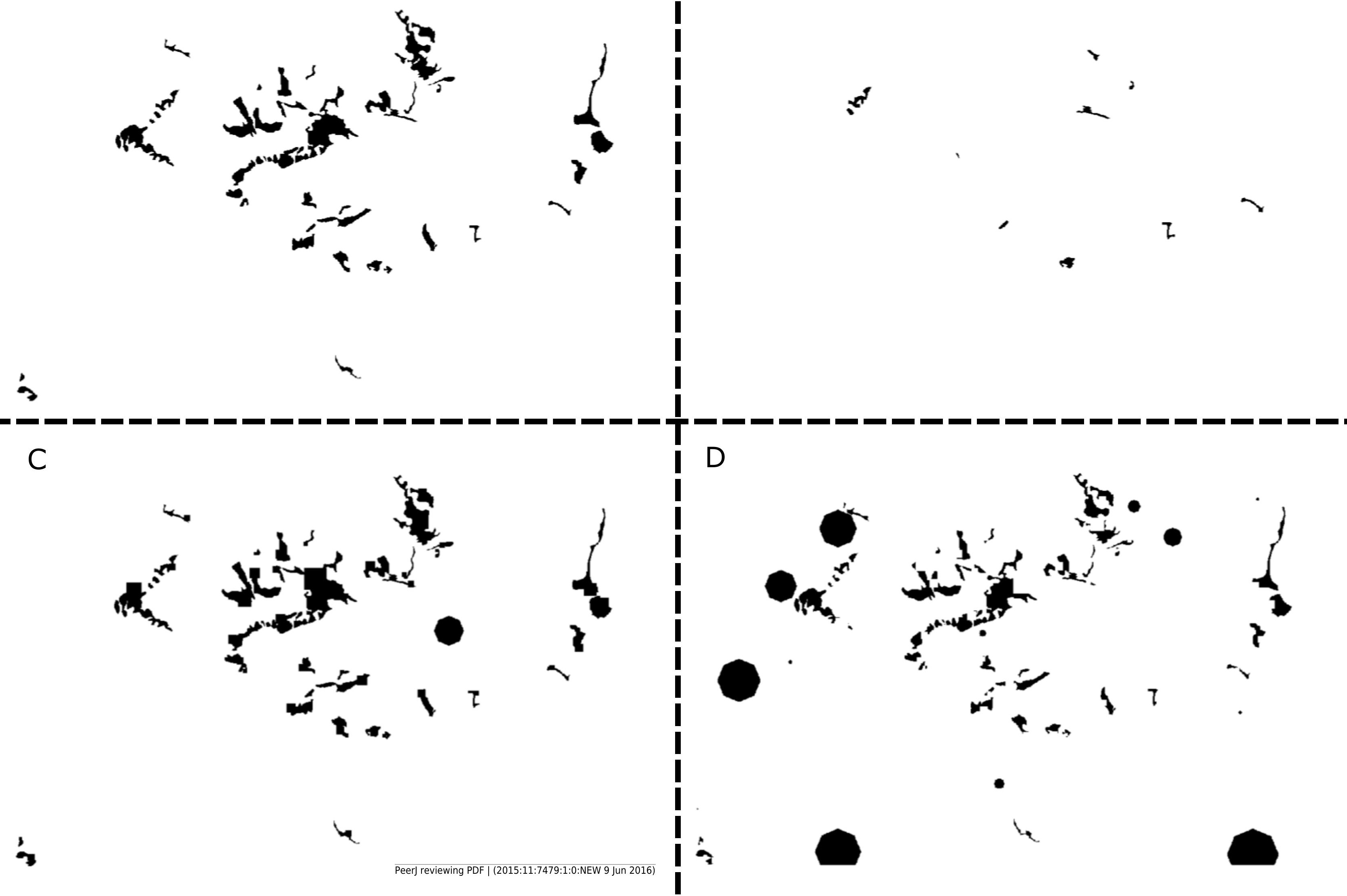




\section{Figure 3 (on next page)}

Partial dependence plots for the four most important predictors of conservation status of the whitebark pine.

The four predictors include: (A) total habitat area, (B) survival class 4, (C) survival class 3a, and (D) catastrophe intensity. Importance was ranked based on each predictors' contribution to reducing the overall model deviance (value in parentheses expressed as a \%).

Conservation status was calculated based on the probability of extinction over a 100-year time period where values $\geqq 0.1$ were considered to be at risk of extinction (status: 1 ) and values $\square 0.1$ were considered not at risk (status: 0 ). This benchmark corresponds to international criteria for listing species as 'Vulnerable'. 

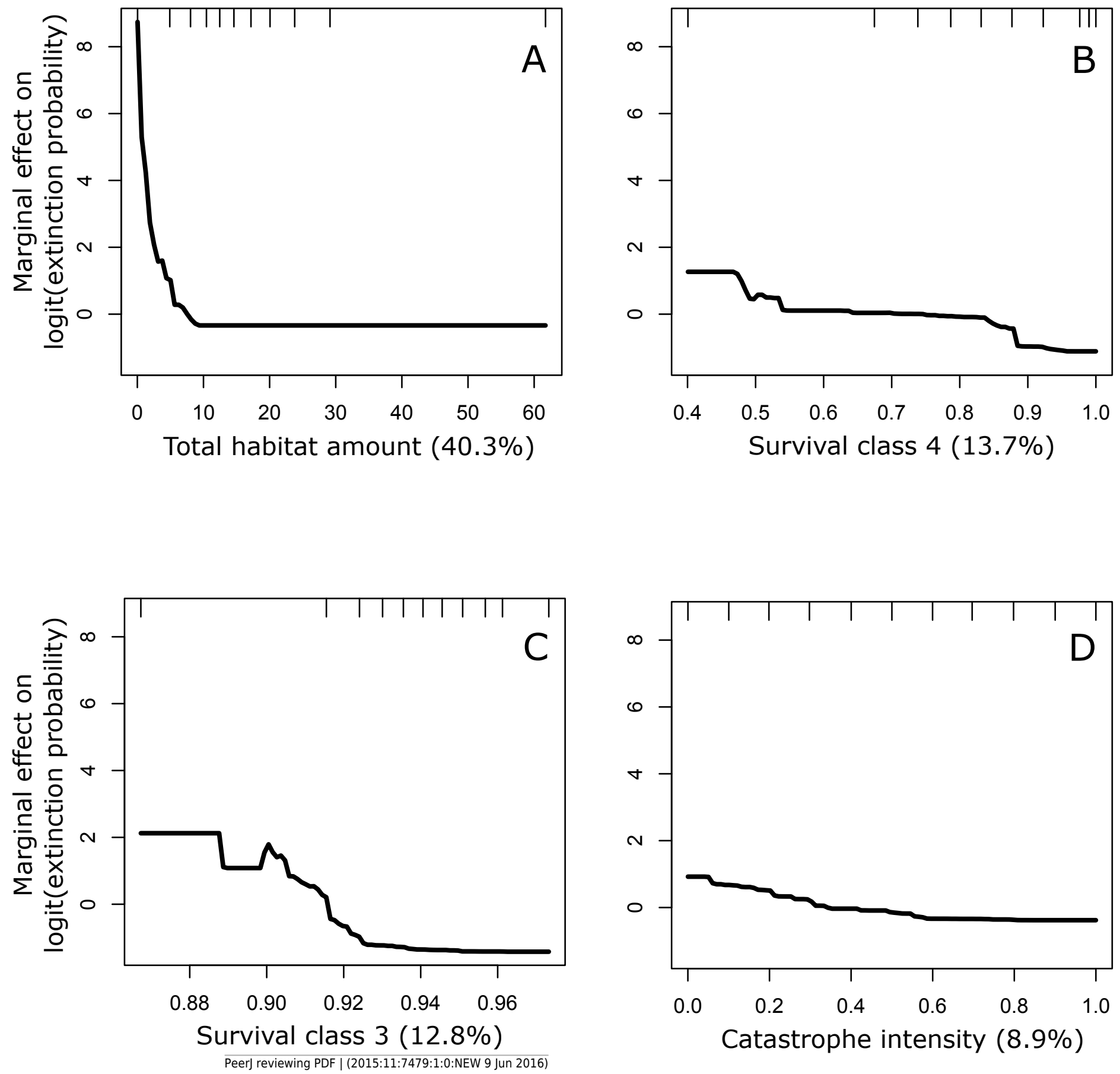
Figure 4(on next page)

Three-dimensional partial dependence plots for the two strongest interactions based on a global sensitivity analysis of the whitebark pine metapopulation model.

All other variables not plotted remain at their mean value. (A) Interaction between total

habitat amount and survival class 4 , and (B) interaction between total habitat amount and catastrophe intensity. 

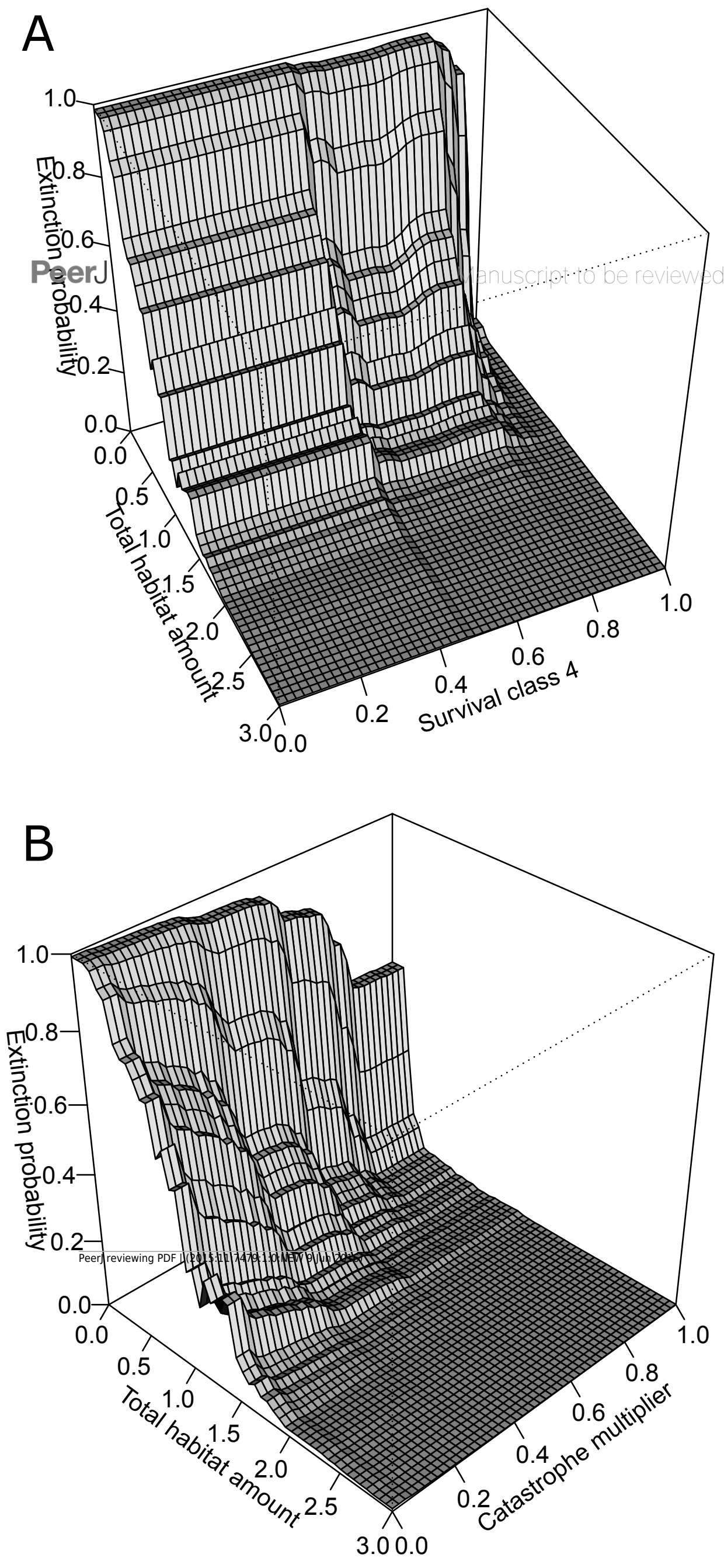


\section{Table $\mathbf{1}$ (on next page)}

Input parameters, sampling distributions and parameter ranges, and brief description of all factors varied in the global sensitivity analysis of the whitepark pine metapopulation coupled species distribution-population dynamics model. 
1 Table 1. Input parameters, sampling distributions and parameter ranges, and brief description of

2 all factors varied in the global sensitivity analysis of the whitepark pine metapopulation

3 population viability analysis. RAMAS module refers to the specific sub-program where the

4 parameter is varied. Parameters varied in RAMAS Spatial are unique to GRIP 2.0, whereas those

5 varied in RAMAS Metapop were introduced in GRIP 1.0 (Curtis and Naujokaitis-Lewis 2008).

6 Parameters with RAMAS Spatial/Metapop specified include habitat-specific environment-

7 demography relationships varied in both modules.

\begin{tabular}{|c|c|c|c|}
\hline Input factor ${ }^{\mathrm{a}}$ & $\begin{array}{l}\text { Distribution and sampling } \\
\text { range }\end{array}$ & Description & $\begin{array}{l}\text { RAMAS } \\
\text { module }\end{array}$ \\
\hline \multirow[t]{3}{*}{$\begin{array}{l}\text { Habitat } \\
\text { suitability } \\
\text { (HS) values }\end{array}$} & $\begin{array}{l}\text { GRIP } 2 \text { has } 4 \text { options for } \\
\text { varying habitat suitability } \\
\text { values: } \\
\text { 1. Random normal: N(mean = } \\
\text { mean of HS values in } \\
\text { original landscape, } \mathrm{SD}= \\
\text { standard deviation of HS } \\
\text { values in original landscape) }\end{array}$ & \multirow[t]{3}{*}{$\begin{array}{l}\text { Spatially explicit } \\
\text { habitat suitability } \\
\text { values, corresponds to } \\
\text { the outputs to the } \\
\text { species distribution } \\
\text { model }\end{array}$} & \multirow[t]{3}{*}{ RAMAS Spatial } \\
\hline & $\begin{array}{l}\text { 2. Spatially-autocorrelated: HS } \\
\text { surface derived from a } \\
\text { simulated gradient where the } \\
\text { degree of spatial } \\
\text { autocorrelation between cell } \\
\text { values can be modified. Uses } \\
\text { functions from the } \\
\text { 'randomFields' R package }\end{array}$ & & \\
\hline & $\begin{array}{l}\text { 3. Ensemble: Uses ensemble } \\
\text { predictions and the measure } \\
\text { of uncertainty to vary new } \\
\text { HS values. Ensembles could } \\
\text { be based on multiple types of } \\
\text { SDM algorithms used to } \\
\text { model species distributions } \\
\text { (e.g., GAM, GLM, RF, } \\
\text { BRT). The current } \\
\text { implementation of GRIP2 }\end{array}$ & & \\
\hline
\end{tabular}




\begin{tabular}{|c|c|c|c|}
\hline Input factor ${ }^{\mathrm{a}}$ & $\begin{array}{l}\text { Distribution and sampling } \\
\text { range }\end{array}$ & Description & $\begin{array}{l}\text { RAMAS } \\
\text { module }\end{array}$ \\
\hline & $\begin{array}{l}\text { resamples HS values using a } \\
\text { random normal variate with } \\
\text { the mean based on the } \\
\text { ensemble prediction for that } \\
\text { gird cell with a SD based on } \\
\text { the uncertainty estimate from } \\
\text { the ensemble model (i.e., the } \\
\text { model-based measure of } \\
\text { variation) for that grid cell. }\end{array}$ & & \\
\hline & 4. Not varied & & \\
\hline & $\begin{array}{l}\text { HS values are rescaled where } \\
\text { the default settings are: the } \\
\text { minimum is the HS threshold } \\
\text { and the maximum is the highest } \\
\text { HS value of the original } \\
\text { landscape. Options exist to } \\
\text { specify a theoretical maximum, } \\
\text { for example where HS values } \\
\text { range from } 0 \text { to } 1 \text {, but no cells } \\
\text { on the original landscape was } \\
\text { estimated at that value. }\end{array}$ & & \\
\hline $\begin{array}{l}\text { Neighborhood } \\
\text { distance }\end{array}$ & $N($ Original value, $10 \% \mathrm{CV})$ & $\begin{array}{l}\text { Used to find distinct } \\
\text { habitat patches, } \\
\text { represents the spatial } \\
\text { scale at which the } \\
\text { population can be } \\
\text { assumed to be } \\
\text { panmictic }\end{array}$ & RAMAS Spatial \\
\hline $\begin{array}{l}\text { Distance } \\
\text { measure } \\
\text { among habitat } \\
\text { patches }\end{array}$ & $\begin{array}{l}D \text { ('edge to edge', 'center to } \\
\text { edge', 'center to center') }\end{array}$ & $\begin{array}{l}\text { Measure used to } \\
\text { calculate the distance } \\
\text { among pairs of patches, } \\
\text { edge and center refer to } \\
\text { the location on the } \\
\text { patch where the } \\
\text { measure starts or ends }\end{array}$ & RAMAS Spatial \\
\hline $\begin{array}{l}\text { Habitat } \\
\text { suitability } \\
\text { threshold }\end{array}$ & $N($ original value, $10 \% \mathrm{CV})$ & $\begin{array}{l}\text { Habitat suitability value } \\
\text { used as the threshold to } \\
\text { distinguish between }\end{array}$ & RAMAS Spatial \\
\hline
\end{tabular}




\begin{tabular}{|c|c|c|c|}
\hline Input factor ${ }^{\mathrm{a}}$ & $\begin{array}{l}\text { Distribution and sampling } \\
\text { range }\end{array}$ & Description & $\begin{array}{l}\text { RAMAS } \\
\text { module }\end{array}$ \\
\hline & & $\begin{array}{l}\text { non-suitable and } \\
\text { suitable habitat on the } \\
\text { raster habitat suitability } \\
\text { map. Any grid cell } \\
\text { value above the } \\
\text { threshold will be } \\
\text { considered for inclusion } \\
\text { as a population (i.e., } \\
\text { habitat patch) }\end{array}$ & \\
\hline $\begin{array}{l}\text { Number of } \\
\text { patches }\end{array}$ & $N($ original number, $50 \% \mathrm{CV}$ ) & & RAMAS Spatial \\
\hline $\begin{array}{l}\text { Initial } \\
\text { abundance }\end{array}$ & $\begin{array}{l}N(\text { mean value per patch is a } \\
\text { function of total habitat } \\
\text { suitability, } \mathrm{CV}=10 \%)\end{array}$ & & $\begin{array}{l}\text { RAMAS } \\
\text { Spatial/Metapop }\end{array}$ \\
\hline $\begin{array}{l}\text { Carrying } \\
\text { capacity }\end{array}$ & $\begin{array}{l}N(\text { mean value per patch is a } \\
\text { function of total habitat } \\
\text { suitability, } \mathrm{CV}=10 \%)\end{array}$ & & $\begin{array}{l}\text { RAMAS } \\
\text { Spatial/Metapop }\end{array}$ \\
\hline $\operatorname{Rmax}$ & $N($ original value, $10 \% \mathrm{CV})$ & Maximum growth rate & $\begin{array}{l}\text { RAMAS } \\
\text { Metapop }\end{array}$ \\
\hline $\begin{array}{l}\text { Catastrophe } \\
\text { extent }\end{array}$ & $D($ local, regional $)$ & $\begin{array}{l}\text { Randomly varies spatial } \\
\text { extent of catastrophe }\end{array}$ & $\begin{array}{l}\text { RAMAS } \\
\text { Metapop }\end{array}$ \\
\hline $\begin{array}{l}\text { Catastrophe } \\
\text { probability }\end{array}$ & $N($ original value, $10 \% \mathrm{CV})$ & $\begin{array}{l}\text { Probability of } \\
\text { catastrophe occurring }\end{array}$ & $\begin{array}{l}\text { RAMAS } \\
\text { Metapop }\end{array}$ \\
\hline $\begin{array}{l}\text { Catastrophe } \\
\text { intensity }\end{array}$ & $N($ original value, $10 \% \mathrm{CV})$ & $\begin{array}{l}\text { Magnitude of } \\
\text { catastrophe effect }\end{array}$ & $\begin{array}{l}\text { RAMAS } \\
\text { Metapop }\end{array}$ \\
\hline $\begin{array}{l}\text { Dispersal } \\
\text { survival }\end{array}$ & $U(0,1)$ & $\begin{array}{l}\text { Proportion of dispersers } \\
\text { that live }\end{array}$ & $\begin{array}{l}\text { RAMAS } \\
\text { Metapop }\end{array}$ \\
\hline Dispersal rate & $N(0,0.1) *$ dispersal rate & $\begin{array}{l}\text { Each dispersal rate is } \\
\text { varied by a constant } \\
\text { value }\end{array}$ & $\begin{array}{l}\text { RAMAS } \\
\text { Metapop }\end{array}$ \\
\hline $\begin{array}{l}\text { Number of } \\
\text { connections }\end{array}$ & $\begin{array}{l}U(0, \text { number of pairwise } \\
\text { population connections } \\
\text { possible })\end{array}$ & $\begin{array}{l}\text { Varies number of } \\
\text { population pairs } \\
\text { connected through } \\
\text { dispersal }\end{array}$ & $\begin{array}{l}\text { RAMAS } \\
\text { Metapop }\end{array}$ \\
\hline $\begin{array}{l}\text { Among- } \\
\text { population } \\
\text { correlation } \\
\text { coefficient of }\end{array}$ & $\begin{array}{l}N(0,0.1) * \text { correlation } \\
\text { coefficient }\end{array}$ & $\begin{array}{l}\text { Varies magnitude of } \\
\text { correlations in vital } \\
\text { rates among population } \\
\text { pairs }\end{array}$ & $\begin{array}{l}\text { RAMAS } \\
\text { Metapop }\end{array}$ \\
\hline
\end{tabular}




\begin{tabular}{|c|c|c|c|}
\hline Input factor ${ }^{a}$ & $\begin{array}{l}\text { Distribution and sampling } \\
\text { range }\end{array}$ & Description & $\begin{array}{l}\text { RAMAS } \\
\text { module }\end{array}$ \\
\hline \multicolumn{4}{|l|}{ vital rates } \\
\hline Seed survival & $L$ (original value, original value) & Seed stage & $\begin{array}{l}\text { RAMAS } \\
\text { Metapop }\end{array}$ \\
\hline $\begin{array}{l}\text { Seedling } 1 \\
\text { survival }\end{array}$ & $L$ (original value, original value) & 1 year old seedling & $\begin{array}{l}\text { RAMAS } \\
\text { Metapop }\end{array}$ \\
\hline $\begin{array}{l}\text { Seedling } 2 \\
\text { survival }\end{array}$ & $L$ (original value, original value) & 2 year old seedling & $\begin{array}{l}\text { RAMAS } \\
\text { Metapop }\end{array}$ \\
\hline $\begin{array}{l}\text { Seedling } 3 \\
\text { survival }\end{array}$ & $L$ (original value, original value) & 3 year old seedling & $\begin{array}{l}\text { RAMAS } \\
\text { Metapop }\end{array}$ \\
\hline $\begin{array}{l}\text { Seedling } 4 \\
\text { survival }\end{array}$ & $L$ (original value, original value) & 4 year old seedling & $\begin{array}{l}\text { RAMAS } \\
\text { Metapop }\end{array}$ \\
\hline $\begin{array}{l}\text { Sapling } \\
\text { mortality }\end{array}$ & $L$ (original value, original value) & Sapling & $\begin{array}{l}\text { RAMAS } \\
\text { Metapop }\end{array}$ \\
\hline $\begin{array}{l}\text { Infected } \\
\text { sapling } \\
\text { survival }\end{array}$ & $L$ (original value, original value) & Infected sapling & $\begin{array}{l}\text { RAMAS } \\
\text { Metapop }\end{array}$ \\
\hline $\begin{array}{l}\text { Nr adult } \\
\text { survival }^{b}\end{array}$ & $L$ (original value, original value) & Non-reproductive adult & $\begin{array}{l}\text { RAMAS } \\
\text { Metapop }\end{array}$ \\
\hline $\begin{array}{l}\text { Infected } \mathrm{n} \\
\text { survival }^{\mathrm{b}}\end{array}$ & $L$ (original value, original value) & $\begin{array}{l}\text { Infected non- } \\
\text { reproductive adult }\end{array}$ & $\begin{array}{l}\text { RAMAS } \\
\text { Metapop }\end{array}$ \\
\hline $\begin{array}{l}\text { Class } \\
1 \text { fecundity } \\
\text { and survival }^{b}\end{array}$ & $L$ (original value, original value) & Healthy adult trees & $\begin{array}{l}\text { RAMAS } \\
\text { Metapop }\end{array}$ \\
\hline $\begin{array}{l}\text { Class } 2 \\
\text { fecundity and } \\
\text { survival }^{b}\end{array}$ & $L$ (original value, original value) & $\begin{array}{l}\text { Branch infected adult } \\
\text { tree }\end{array}$ & $\begin{array}{l}\text { RAMAS } \\
\text { Metapop }\end{array}$ \\
\hline $\begin{array}{l}\text { Class } 3 \\
\text { fecundity and } \text { survival }^{\mathrm{b}}\end{array}$ & $L$ (original value, original value) & Bole infected adult tree & $\begin{array}{l}\text { RAMAS } \\
\text { Metapop }\end{array}$ \\
\hline $\begin{array}{l}\text { Class } 4 \\
\text { fecundity and } \\
\text { survival }^{b}\end{array}$ & $L$ (original value, original value) & $\begin{array}{l}50 \% \text { crown loss } \\
\text { infected adult tree }\end{array}$ & $\begin{array}{l}\text { RAMAS } \\
\text { Metapop }\end{array}$ \\
\hline
\end{tabular}

8 a Selected distributions and their parameters: $D=$ discrete distribution (discrete value ${ }_{1}$, discrete

$9 \operatorname{value}_{x}$ ), where each value has equal probability of selection; $N=$ normal distribution (mean, 
10 standard deviation -sometimes expressed in terms of coefficient of variation, $\% \mathrm{CV}) ; L=$

11 lognormal distribution (mean, standard deviation); $U=$ uniform distribution (minimum,

12 maximum)

$13{ }^{\mathrm{b}}$ Denotes that the stage was included in the model of density dependence 


\section{Table 2 (on next page)}

Relative contribution of the ten most important variables to extinction status of the whitebark pine based on the 2-way interaction boosted regression tree. 
1 Table 2. Relative contribution of the ten most important variables to extinction status of the

2 whitebark pine based on the 2-way interaction boosted regression tree.

\begin{tabular}{lrr}
\hline Variable & Relative contribution (\%) & Type of variable \\
\hline Total habitat amount & 40.3 & Habitat \\
Survival class 4 & 13.7 & Demographic \\
Survival class 3 & 12.8 & Demographic \\
Catastrophe intensity & 8.9 & Demographic \\
Mean carrying capacity & 5.9 & Habitat \\
Mean correlations & 2.6 & Demographic \\
Mean habitat suitability & 1.8 & Habitat \\
Mean dispersal rate & 1.5 & Demographic \\
Fecundity class 1 & 1.2 & Demographic \\
No. of populations & 1.1 & Habitat
\end{tabular}

3 